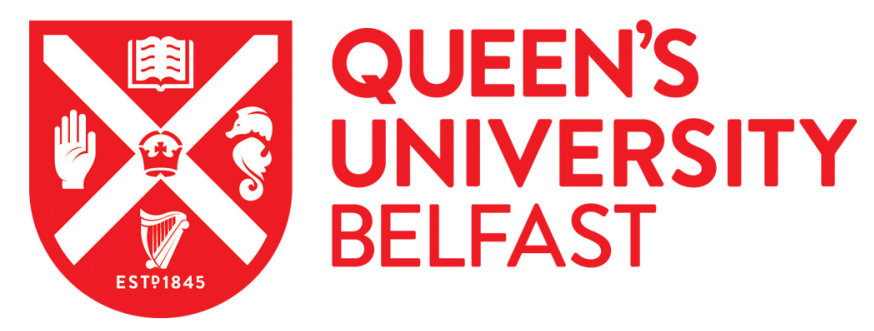

\title{
Increased aggressive motivation towards formidable opponents: Evidence of a novel form of mutual assessment
}

Kareklas, K., McMurray, R., \& Arnott, G. (2019). Increased aggressive motivation towards formidable opponents: Evidence of a novel form of mutual assessment. Animal Behaviour, 153, 33-40.

https://doi.org/10.1016/j.anbehav.2019.04.013

Published in:

Animal Behaviour

Document Version:

Peer reviewed version

Queen's University Belfast - Research Portal:

Link to publication record in Queen's University Belfast Research Portal

\section{Publisher rights}

Copyright 2019 Elsevier.

This manuscript is distributed under a Creative Commons Attribution-NonCommercial-NoDerivs License

(https://creativecommons.org/licenses/by-nc-nd/4.0/), which permits distribution and reproduction for non-commercial purposes, provided the author and source are cited.

\section{General rights}

Copyright for the publications made accessible via the Queen's University Belfast Research Portal is retained by the author(s) and / or other copyright owners and it is a condition of accessing these publications that users recognise and abide by the legal requirements associated with these rights.

Take down policy

The Research Portal is Queen's institutional repository that provides access to Queen's research output. Every effort has been made to ensure that content in the Research Portal does not infringe any person's rights, or applicable UK laws. If you discover content in the Research Portal that you believe breaches copyright or violates any law, please contact openaccess@qub.ac.uk. 
1 Title:

2 Increased aggressive motivation towards formidable opponents: Evidence of a novel form of 3 mutual assessment

4 Authors:

5 Kyriacos Kareklas ${ }^{1 *}$, Rebekah McMurray ${ }^{1}$, Gareth Arnott ${ }^{1}$

6

7 Affiliations:

$8{ }^{1}$ School of Biological Sciences, Queen's University Belfast, 97 Lisburn Road, Belfast, N.

$9 \quad$ Ireland, BT9 7BL, UK

10 *Corresponding author; email: kkareklas01@qub.ac.uk

11

12

13

14

15

16

17

18

19

20

21

22 


\section{ABSTRACT:}

Contests are largely driven by resource value, but their outcome also depends on asymmetries in fighting ability between contestants. Consequently, individuals benefit from assessing these asymmetries when deciding to engage opponents or retreat. Yet, there is much about these assessments that we do not know. First, it is often difficult to discriminate if individuals only assess their own fighting ability or if they compare it to that of their opponents by mutual assessment. Second, the extent to which assessment improves over the course of a contest, as predicted by theory, has remained largely unexplored. We addressed these questions by studying assessment during territorial contests between male Siamese fighting fish, Betta splendens. Findings show the consistent use of mutual assessment when deciding to engage opponents, with a progressive increase in assessment accuracy over sequential contest phases by reducing the use of dishonest signals. Importantly, contrary to theoretical expectations, we find evidence of a novel form of mutual assessment in which fight motivation increases (rather than decreases) when contestants assess their opponents as more formidable than themselves. Although contestants shifted to opponent-only assessment when adjusting display and attack, the collective evidence shows greater aggressive intent towards more threatening opponents. We argue that explanations for this form of assessment may be provided by considering territorial dynamics related to reproductive success and parental investment.

Keywords: decision accuracy; dishonest signals; fighting ability; mutual assessment; territorial contests. 


\section{INTRODUCTION}

Contests are ubiquitous in the animal kingdom and constitute an important component of social interactions that contributes to fitness (Briffa \& Hardy, 2013). On one hand, contests can play a crucial role in driving resource allocation, such as food or territory, and can be used to resolve existing issues in resource distribution, where the scarcity of a resource may increase motivation to compete for it (Enquist \& Leimar, 1987; Arnott \& Elwood, 2008). On the other hand, contests are energetically demanding and fights against more formidable opponents can be damaging to health, with an increased mortality risk from escalated injurious attacks (Enquist \& Leimar, 1983; Riechert, 1988; Neat, Taylor and Huntingford, 1998). Therefore, contestants may adjust their fighting strategy depending on the potential costs they may sustain.

Game theory has extensively addressed the way that potential costs and benefits affect contest outcome, focusing largely on the role of asymmetries between contestants (Riechert, 1998). Classical models assume that contestants may exhibit only one of few stable fighting strategies (e.g. Hawks vs. Doves; Smith \& Price, 1973) and maintain fixed decisions during contests (Smith \& Parker, 1976). Yet the ability of contestants to attain resources is determined by a range of factors, collectively termed resource holding potential (RHP; Parker, 1974), which include body size, residency, weaponry, energetic state and kinship (Briffa, 2008; Walsh \& Iyengar, 2015). Consequently, fighting strategy can vary extensively and continuously with these RHP factors and as a result of the cognitive assessment of information on these factors by contestants, a concept that has been increasingly supported by empirical evidence (Arnott \& Elwood, 2009a; Reichert \& Quinn, 2017). However, RHP assessment is not yet well understood and identifying particular assessment strategies remains difficult (Taylor \& Elwood, 2003; Arnott \& Elwood, 2009a). 
For contestants, the most accurate estimate of asymmetries comes from mutual assessment ('sequential assessment model'; Enquist, Leimar, Ljungberg, Mallner \&

Segerdahl, 1990) where they sequentially gather information on relative differences in RHP between themselves and an opponent, typically interpreted as a comparison of ability (Elwood \& Arnott, 2012). However, early support for this strategy was based on incorrect analyses (Taylor \& Elwood, 2003), with few recent convincing examples of its use by animals (Schnell, Smith, Hanlon \& Harcourt, 2015; Green \& Patek, 2018). In contrast, self assessment strategies, where animals evaluate only their own RHP ['war of attrition without assessment' (Mesterton-Gibons, Marden \& Dugatkin, 1996) and 'energetic war of attrition' (Payne \& Pagel, 1996) models], have increasing empirical support (Prenter, Elwood \& Taylor, 2006; Elwood \& Arnott, 2009a; Tsai, Barrows \& Weiss, 2014). Although asymmetry cannot be directly estimated without comparisons to opponent RHP, they can be reflected in estimates of thresholds when animals evaluate their own RHP sequentially over fights and consider changes due to injury sustained ('cumulative assessment model'; Payne, 1998). In particular, because opponents with greater fighting ability can inflict greater injury, this can reflect effects related to opponent RHP. Consequently, mutual assessment is difficult to distinguish from cumulative self-assessment because they both result in the same predictions for relationships between contestant RHP and contest costs (Taylor \& Elwood, 2003; Arnott \& Elwood, 2009a). Indeed, many recent studies using the framework of examining relations between contestant RHP and contest costs have produced inconclusive results in terms of support for a particular strategy (e.g. Prenter, Elwood \& Taylor, 2006; Martínez-Cotrina, BohórquezAlonso \& Molina-Borja, 2014; McGinley, Prenter \& Taylor 2015). These studies use measures that indicate direct costs (e.g. degrees of attack escalation and outcome) or cost thresholds (e.g. contest duration) related to the progress of a fight, but assessment is expected 
to differ when deciding to engage in a fight. This is because the decision to retreat before engaging provides benefit to those likely to lose or incur injury and because during fights behaviour may reflect mostly immediate responses to the opponent (Mesterton-Gibbons \&

100 Heap, 2013). Therefore, it is equally important to also consider RHP effects on the 101 motivation to fight. Although contest duration is also considered an indicator of motivation, 102 the length of a contest relies largely on ongoing behaviour and specifically relates to loser motivation, because longer durations indicate a greater cost threshold contestants are willing to accept before retreating (Arnott \& Elwood, 2009b). Thus, there is a need for alternative approaches to infer assessment and one such alternative is to probe aggressive motivation

106 directly. To achieve this, Elwood, Wood, Gallagher \& Dick (1998) interrupted fights by

107 startling focal contestants and measured the time they remained startled (motionless) before resuming activity, which indicated their willingness to engage opponents. That study and a number of studies since (e.g. Arnott \& Elwood, 2009b; Arnott \& Elwood, 2010a; Schnell et al., 2015), have validated startle duration as a strong indicator of aggressive intent and fight

111 motivation that is independent of in-fight behaviour and fight outcome, i.e. whether focal

112 contestants lose or win. Another advantage of the startle probe is that it can be used more 113 than once during fights (Arnott \& Elwood, 2010), enabling changes in assessment strategy to

114 be tracked over the course of the contest. Predictions are that if animals use RHP assessments 115 when deciding to engage an opponent, then startle durations will vary with own RHP if they 116 use self assessment, with opponent RHP if they use opponent assessment and with both if 117 they use mutual assessment (Arnott \& Elwood, 2009a). Furthermore, as the contest 118 progresses animals are expected to have more opportunity to collect and analyse information 119 from their opponent, which is why progressive improvements over time are particularly 120 expected for opponent and mutual assessment (Enquist et al., 1990; Payne, 1998). 
We employed the startle probe technique on two sequential occasions during fights in captive-bred male Siamese Fighting fish (Betta spelndens) to examine whether motivation to engage opponents is affected by own and opponent RHP measures and if the effect changes over time. By also looking at agonistic behaviour, we further aimed to examine similarities in decision strategy between engaging opponents and responding to their display and attack during fights. Further, by staging interactions between tanks (through the transparent tank walls) we prohibited direct contact and injury, and ensured fish could assess opponent RHP only via visual assessment. Although we found no studies explicitly examining the contribution of $B$. splendens body size to RHP, body weight and length have been extensively

130 validated across species, including fish (see Arnott \& Elwood, 2009a) and, therefore, are expected to provide a reliable indicator of RHP. On the contrary, while fins may be implicated in the attack repertoire of $B$. splendens (tail beating, fin flickering and charging; Simpson, 1968), effects of fin size on contest behaviour have only been indicated by response to images (Allen \& Nicoletto, 1997) and there is no other evidence that they honestly signal RHP. However, because captive-bred lines of the species commonly have fins larger or smaller than would be expected for their body size (Meejui, Sukmanomon \& Na-Nakorn, 2005), fin size may misrepresent RHP by influencing assessment of size (Payne \& Pagel, 1997; Earley, 2010) and bias behaviour due to signal dishonesty. In particular, we consider the degree to which fin size is disproportionate to body weight (a measure of size widely

140 validated as an indicator of RHP) to indicate the extent to which fins can dishonestly signal 141 size during display. As such, in addition to using weight as a robust measure of RHP, we also examine if fin display provides a parallel dishonest signal by exaggerating size. This is achieved by examining the residuals of the linear relationship between fin length and body

144 weight, a measure that indicates the degree to which fin size is disproportionate to body size 145 (see Elwood and Arnott, 2010b). We predicted that motivation and aggression would be 
146 greater for fish with a high RHP if self assessment is used (such as in killifish; Hsu, Lee,

147 Chen, Yang \& Cheng, 2008) and lower towards high RHP opponents if opponent assessment

148 is used (such as in the cichlid Neolamprologus pulcher; Reddon, Voisin, Menon, Marsh-

149 Rollo, Wong et al., 2011), and that both these predictions should be met if mutual assessment

150 is used. Further, if mutual assessment is used we also expect a lower fight motivation and aggression towards opponents that have a relatively greater advantage in RHP (RHP asymmetry; Schnell et al., 2015; Green \& Patek, 2018). Finally, we expected that effects from signal dishonesty would decrease during contests, if assessments progressively improve as predicted by theory (Enquist et al., 1990; Payne, 1998).

\section{METHODS}

Animals and husbandry

Male Siamese fighting fish $(N=44)$ were acquired from a local supplier, Grosvenor Tropicals, Lisburn, Northern Ireland. Fish were housed individually in $15 \mathrm{~L}$ tanks enriched

160 with plants, toys and shelter. Tank water was filtered, heated, aerated and changed twiceweekly, kept at $26 \pm 1{ }^{\mathrm{O}} \mathrm{C}, 7.2 \pm 0.4 \mathrm{pH}$ and a regulated bacterial cycle. Together with the highly monitored conditions, regular checks were carried out to ensure fish were healthy and without signs of common diseases (as listed by Monvises, Nuangsaeng, Sriwattanarothai \& Panijpan, 2009). Each fish was fed 4 pellets (Hikari@ Bio-gold) twice a day and exposed to 165 regular $12 \mathrm{~h}$ photoperiods (0700-1900). Experiments were carried out during light periods 166 (350-600 nm and 300 lux at water surface).

\section{Ethical note}

This study was carried out in accordance with all relevant animal-welfare guidelines (ASAB). Our experimental set-up prevented direct physical contact between fish, removing any risk of injury, and our protocol kept staged contests brief, reducing contest-related stress 
171 levels (as recommended by Huntingford, 1984). By minimising transfers and always transporting fish in water we limited stress from handling and disturbance. Veterinary inspections by DHSSPS, Northern Ireland, deemed no need for licensing and an institutional

174 ethical approval was acquired (No.: QUB-BS-AREC-17-004). Following the conclusion of

175 the study, animals were kept for separate non-invasive tests.

\section{RHP measures}

After a 72-hour acclimation to laboratory conditions, two RHP measures were recorded for all fish. First, wet weight in grams was used as a robust estimate of RHP (Arnott \& Elwood, 2009), calculated using a digital precision scale to estimate the net weight

180 between the tare weight of a water-filled container and its weight when holding the fish.

181 Second, the length of the caudal fin (Figure 1a) and the anal fin (Figure 1b) were estimated from traces on graph paper applied to the outside of the tank when fish rested and used as an indicator of general fin size, a visual signal that could potentially dishonestly advertise RHP. All fish rested on $3 \mathrm{~cm}$ wide buoyant platforms that were attached near the surface on the

185 front facing glass wall of the tank (to facilitate breathing during resting times), which ensured 186 fish were against the glass wall during measurements and minimised variation in the distance 187 from the wall between individuals. Because visual attention to each fin might vary due to individual strategy or differences in opportunity (e.g. opponents exhibiting more lateral display provide more opportunity for focal fish to assess their caudal fin), we used the

190 combined fin length to indicate fin size. This enabled the examination of composite effects

191 from fin size, controlling effects due to differences in attention to either fin.

\section{Contests}

Two days following weight and fin length measurements, we randomly selected focal

194 fish $(N=22)$ and paired them with an opponent $(N=22)$, matching half of the focals with an 195 opponent bigger than them and half with an opponent smaller than them (using weight 
196 comparisons) in a randomised fashion and housing pairs in neighbouring tanks. Opaque 197 plastic sheets were placed between neighbouring housing tanks to prevent interactions, which 198 mitigated behavioral effects from heightened aggressiveness (Gómez-Laplaza \& Morgan, 199 2000) and prior fighting experience (Hsu, Earley \& Wolf, 2006). The first contests were 200 carried out following a 7-day acclimation period to the new housing tanks, which allowed 201 fish to form territorial associations. Following their first contest, focal fish were randomly matched with a new opponent so that individuals that first faced a bigger opponent were now matched with a smaller opponent and those that first faced a smaller opponent were now matched with a bigger opponent. New opponents were moved to the tanks next to focal fish and allowed to acclimatise for 7 days before the second contest.

At the start of each contest, the opaque dividers between the neighboring tanks of pairs were removed and fish allowed to interact across the glass tank walls. Although the airwater interface between tanks may lead to some visual distortions, evidence in $B$. splendens (Arnott, Beattie \& Elwood, 2016) and other fish suggests that this set-up enables the visual 210 assessment of opponents (Arnott \& Elwood, 2010a) and ensures that there are no effects from 211 direct contact. Contests were video recorded using a Sony HDR CX190E handy-cam video 212 camera oriented towards the front facing walls of the two tanks, so that both focal and 213 opponent fish could be recorded. A large plastic panel $(150 \mathrm{~cm}$ x $150 \mathrm{~cm})$ was placed behind 214 the camera to hide the experimenter when controlling the camera and carrying out test-related 215 manipulations. For the interim periods, the experimenter remained away from the tanks to 216 minimise any further interference. A large glass marble (24g) was dropped through a hole in 217 a plastic panel placed on top of the tank of the focal fish, 2 min after the onset of display 218 (identified as either frontal display - presenting extended gills to opponent- or lateral display 219 - presenting side with flared fins to opponent; Simpson, 1968). The panel was kept at $10 \mathrm{~cm}$ 220 from the water surface allowing the marble to land in the water with a distinct splash and act 
as a startling stimulus. The marble landed behind a vertical opaque plastic screen $(21 \mathrm{~cm} \mathrm{x}$ $5 \mathrm{~cm}$ ) placed in the tank of the focal fish 10 min prior to experimentation (the time serving as an acclimation period), so that it hid the startle stimulus from the opponent (as per Arnott \& Elwood, 2009b \& 2010a). Once the focal fish resumed display, behaviour was recorded for a further $5 \mathrm{~min}$ before dropping a second marble using the same approach. Following recommencement of display from the second startle, fish were allowed to display for a final period of 5 min before the test was concluded by replacing the opaque plastic sheet between tanks.

From the video recordings, we measured two separate aspects of agonistic behaviour: (1) the total duration (seconds) of agonistic display by each contestant, including the extension of gill opercula when facing the opponent (frontal display) and the presentation of their side to the opponent while swimming and flaring their fins (lateral display); (2) the total number of attempted attacks by each contestant identified either as tail beating (within $\sim 1$ body length proximity to the tank wall and oriented towards opponent) or biting (charging the tank wall with their mouth open and oriented towards opponent) (Simpson, 1968). Finally, we measured the time (in seconds) focal fish remained motionless following the drop of the marble (from when the marble hit the water), which was used as a measure of fight motivation (referred to as startle duration; Elwood et al., 1998; Arnott \& Elwood, 2010a).

\section{Analysis}

All calculations, analyses and graphical representations were carried out in the statistics software Minitab ${ }^{\circledR}$ version 17 (Minitab Inc., State College, PA, USA) and SPSS version 22 (IBM Corp., Armonk, NY. USA). First, the degree of signal dishonesty was

244 measured by the residuals of the linear regression between combined fin size and weight, for 245 both opponent and focal fish, which indicated the degree of disproportion between the two 
measures (see Arnott \& Elwood, 2010b). All dependent measures and predictors

247 (Supplementary; Table S1) were normally distributed (parametric), with the exception of the

248 recorded number of attacks during contests (non-parametric measure). Mean differences in

249 startle duration between sequential probes and in total display duration between fights with

250 bigger or smaller opponents were tested using repeated measures ANOVA. Differences in

251 the median number of attacks (non-parametric) between fights with bigger or smaller opponents were tested by Wilcoxon signed-ranks test. Separate mixed-effect models were used to test for effects from RHP measures, examining linear associations with parametric variables and Poisson associations (log-link) with the non-parametric variable. First, models were used to test main effects from focal-weight, opponent-weight and their difference, to establish links to an accurate RHP indicator. Second, models were used to test main effects from the residuals of the regression of total fin length on wet weight, from opponents, focals, and their difference, to establish effects from dishonest signals. All mixed models included ID as a random factor to control for pseudoreplication. Furthermore, trial (first or second contest), opponent sequence (i.e. whether bigger or smaller opponents were faced first) and their interaction were included as fixed effects to test for influences of experience between contests.

\section{RESULTS}

Mean startle durations did not differ between the first and second probe $\left(\eta^{2}=0.068\right.$,

$\left.266 F_{2,22}=1.54, P=0.068\right)$, but were longer $\left(\eta^{2}=0.160, \quad F_{2,22}=4.00, P=0.059\right)$ when fighting

267 relatively smaller opponents (startle $1:$ mean $=56.27 \mathrm{~s} \pm 92.78$ S.D., startle $2:$ mean $=78.41 \mathrm{~s}$

$268 \pm 141.35$ S.D.) than relatively bigger opponents (startle 1: mean $=29.63 \mathrm{~s} \pm 58.83$ S.D., 269 startle $2:$ mean $=36.00 \mathrm{~s} \pm 55.13$ S.D.). No significant differences in mean display times 
$270 \quad\left(\eta^{2}=0.047, F_{2,22}=1.027, P=0.322\right)$ or median attack attempts $\left(Z_{2,22}=-0.958, P=0.338\right)$ were

271 found between contests with bigger or smaller opponents.

272

273

274

275

276

277

278

280

281

282

283

284

285

286

287

288

289

290

291

292

293

\section{RHP effects on fight motivation and agonistic behaviour}

Startle durations were not affected by trial, opponent sequence (bigger or smaller first) or their interaction $\left(r^{2}<0.09 ; P>0.05\right)$, indicating no experience effects between contests. Both the first and second startle duration of focal fish were related positively to their own wet weight, negatively to the wet weight of their opponents and strongly linked to the degree and direction in which they differed from the opponent (Table 1a), with shorter startle durations exhibited by smaller fish (Fig. 2a) towards bigger opponents (Fig. 2b) that were also bigger in relation to themselves (Fig. 2c). This indicates that motivation relied on own and opponent RHP, as well as the asymmetry in RHP, as expected for the use of mutual assessment.

Behaviour during fights, display times and attack numbers, were not affected by trial, opponent sequence or their interaction $\left(r^{2}<0.01 ; P>0.05\right)$. However, both total display times $\left(r^{2}=0.159, F_{2,44}=7.66, P=0.009\right)$ and the number of attacks $\left(r^{2}=0.125, \chi_{2,44}^{2}=17.19, P<0.001\right)$ were related positively to opponent weight (Fig. 3a and 3c), but not own weight (total display time: $r^{2}=0.044, F_{2,44}=2.13, P=0.152$; number of attacks: $r^{2}=0.002, \chi^{2} 2,44=0.32, P=0.569$; Fig. $3 b$ and $3 \mathrm{~d}$ ) or the weight difference between contestants (total display time: $r^{2}=0.081$, $F_{2,44}=3.63, P=0.064$; number of attacks: $\left.r^{2}=0.020, \chi^{2} 2,44=2.82, P=0.093\right)$. Collectively, these results support the hypothesis that agonistic behaviour was depended on opponent RHP (i.e. opponent assessment), but not own RHP (self assessment) or asymmetries between the two (mutual assessment).

\section{Fin length as a dishonest signal of RHP}

Combined fin length was positively related to wet weight, for both focal $\left(R^{2}=0.154\right.$, 
a significant lack-of-fit error in the model with instances of fish having exceedingly larger or smaller fins than predicted by their weight, both for focals $\left(R^{2}=0.755, F_{2,22}=16.78, P<0.001\right)$ and opponents $\left(R^{2}=0.602, F_{2,22}=4.34, P<0.001\right)$. Given that weight is a widely validated measure of RHP (studies cited in Arnott \& Elwood, 2009a), this suggests that fin length can signal RHP but with a significant degree of inaccuracy. The extent to which RHP is misrepresented by fin length, as indicated by the residuals from the regression, was not found related to total display time (focal resid.: $R^{2}=0.0014, F_{2,44}=0.06, P=0.812$; opponent resid.: $R^{2}=0.020, F_{2,44}=0.81, P=0.372$; difference: $\left.R^{2}=0.005, F_{2,44}=0.21, P=0.651\right)$ or the number of attacks (focal resid.: $R^{2}=0.013, \chi_{2,44}^{2}=1.75, P=0.186$; opponent resid.: $R^{2}=0.020, \chi_{2,44}^{2}=2.72$, $P=0.099$; difference: $R^{2}=0.003, \chi^{2} 2,44=0.38, P=0.537$ ). This suggests that fin size was not used for adjusting agonistic behaviour. Conversely, startle duration was related to the residuals of focal and opponent fish, and their difference in residuals, which suggests that fin size is used during assessment. However, the relationship was not consistent over time, being significant for the first startle but not the second startle (Table 1b).

\section{DISCUSSION}

312 their opponent's fighting ability, which is used to assess asymmetries. This is evidenced by

313 fight motivation being affected by own and opponent measures of RHP, and also by the degree and direction of asymmetry between contestants (Fig. 2 and Table 1). Given the lack of contact or injury during fights, this evidence strongly suggests that fish use visual signals from the opponent which indicates mutual assessment as predicted by theory (Payne, 1998; Taylor \& Elwood, 2003; Arnott \& Elwood, 2009a). More specifically, we find evidence for a novel form of mutual assessment in which, contrary to theoretical predictions (e.g. sequential assessment model; Enquist etal., 1990), aggressive motivation increases (rather than 
decreases) when facing a more formidable opponent. These findings highlight how the identification of any form of assessment primarily relies on whether measures of own RHP, opponent RHP and asymmetries between them predict variation in contest behaviour and to what degree, with the direction of effects only indicating how the assessment is used and not whether it is used.

Our results compare variably to previous findings showing that $B$. splendens (Polgardani, Rouzbehani \& Parsaiyan, 2017) and other fish species (Reddon et al., 2011) estimate opponent RHP, but offering no evidence for mutual assessment. On the contrary, some earlier studies suggest that teleost fish exhibit mutual assessment of RHP measures, including fin size and weight (Enquist, Ljunberg \& Zandor, 1987; Turner, 1994). However, these earlier studies only consider differences between bigger and smaller asymmetry pairs to support this, which, as noted by Taylor \& Elwood (2003), can be driven solely by own-RHP assessments and can misrepresent the strategy used. Examples of mutual assessment identified by linear relationships, as predicted by updated theory (Arnott \& Elwood, 2009a; Elwood \& Arnott, 2012), can only be found in studies of other taxa that sometimes use startle probes to measure fight motivation (e.g. cuttlefish; Schenll et al., 2015), but more frequently infer motivation from contest duration (e.g. mantis shrimp; Green \& Patek, 2018). As noted in the introduction, studies indicate important advantages of using startle probes to measure motivation over inferring motivation from contest duration, including independence of startle responses from ongoing agonistic behaviour and outcome, i.e. whether a focal individual

340 wins or loses (Elwood et al., 1998; Arnott \& Elwood, 2009b; Arnott \& Elwood, 2010a).

341 Therefore, by using startle probes in our study, we provide evidence for mutual assessment in fish contests that rely on an independent and more robust measure of motivation.

In contrast to evidence of mutual assessment when deciding to engage opponents,

344 agonistic behaviour during fights relied only on visual assessments of the opponent's RHP 
345 (Fig. 3). The aggressive responses of $B$. splendens have been previously found to peak even 346 in the presence of only artificial cues that cannot be accurately assessed or compared to own 347 ability (including LED lights and robotic movement; Romano, D., Benelli, G., Donati, E., 348 Remorini, D., Canale et al., 2017). Consequently, aggression during fights may reflect a 349 generalised response to perceived levels of directed threat, for which size can be an indicator 350 (e.g. cichlids are more aggressive towards bigger dummies; Beeching, 1992). Consistent with earlier evidence in fish (killifish; Hsu et al., 2008) and with theory (Mesterton-Gibbons \& Heap, 2013), this suggests that, while engaging in fights might rely on more accurate assessments that involve greater effort, animals rely on simpler mechanisms for adjusting response during display and attack.

One morphological feature used by $B$. splendens to signal RHP and assess opponents is fin size (Allen \& Nicoletto, 1997), facilitated by lateral displays during contests (Simpson, 1968; Monvises et al., 2009). Here we identify that fin size can misrepresent size by either being bigger or smaller than would be expected by weight, an extensively validated measure of RHP across vertebrates (see review by Arnott \& Elwood, 2009a). Similar to earlier studies

360 measuring signal dishonesty (Arnott \& Elwood, 2010b), this was indicated by values of 361 regression residuals between fin size and weight. The degree of misrepresentation affected contestant motivation (startle duration), with respect to their own and their opponent's fin residuals, as well as difference between the two (Table 1). This suggests that the misrepresentation of the signal is both used by focal contestants (as senders) and influences their behavior when assessed in opponents (as receivers), suggesting its use as a dishonest signal as expected by literature (Payne \& Pagel, 1997; Earley, 2010). However, contrary to

367 the consistency of effects of wet weight between the first and second startle probe (Figure 2), 368 the effects on fight motivation by fin size residuals progressively decrease over sequential 369 probes and lose statistical significance (Table 1). If fin size was assessed by fish as an 
independent RHP measure, due to the involvement of fins during attacks (Simpson, 1968), we would expect stable effects over time. However, we considered fin size as a signal of overall size and here we identify that the degree of its dishonesty as a signal of size has a decreasing effect over time. The progressive decrease in effects from unreliable information is consistent with an expected progressive increase of assessment accuracy during contests

375 (Elwood \& Arnott, 2012) and possibly reflects the involvement of learning and attentional control in regulating motivation (Reichert \& Quinn, 2017). Though we cannot be certain about learning effects from our findings, we can infer the progressive increase in assessment accuracy via the decreased efficacy of dishonest signals.

The increase in fight motivation towards formidable opponents, as a result of such accurate and progressively improved estimates of RHP symmetries, is more difficult to explain. Contrary to predictions from theory (Arnott \& Elwood, 2009a; Elwood \& Arnott, 2012), fish were more motivated to fight opponents that they assessed as having a greater RHP than them (Fig. 2). Fighting relatively stronger opponents increases the risk of incurring costs (Riechert, 1988; Neat et al., 1998), which can initially seem maladaptive. Explanations for unexpected levels of fight motivation during territorial disputes are often attributed to owner-intruder dynamics, where owners are more informed on the objective value of their territory than intruders and ownership is expected to provide an RHP advantage independent of fighting ability (Enquist \& Leimar, 1987; Smith \& Parker, 1976; Arnott \& Elwood, 2008; Arnott \& Elwood, 2009a). Another possibility is that territorial owners unconditionally

390 decide to engage in fights because the more frequently they win, the less likely intruders will compete with them in the future (Kokko, López-Sepulcre, A., \& Morrell, 2006). However, these two hypotheses assume that fight motivation is dependent on being either an owner or an intruder, but not on RHP asymmetries, which contrasts our findings. An alternative hypothesis is the 'desperado effect' (Grafen, 1987), where less formidable animals with a 
history of losing do not respect ownership-based asymmetries in RHP over an extremely valuable resource. Although this hypothesis implicates resource value in the unexpectedly high aggression of low-RHP fish (Fig. 2a), it also assumes no respect for RHP asymmetries. Therefore, it also cannot explain the mutual assessment strategy revealed in our study that drives individual fight motivation towards relatively bigger opponents (collective evidence;

400 Fig. 2).

A more plausible explanation is offered by the Napoleon strategy, which relies on accurate estimates of asymmetries in RHP and resource value; the strategy involves the expression of elevated aggressive intent by small males towards opponents assessed to be comparatively more formidable, especially when the value of a resource is higher than the costs of the contest (Morrell, Lindström \& Ruston, 2005). It is likely that fish with a lower RHP, that are likely to have been out-competed in the past, may attribute greater value to established territory and be more likely to fight threatening opponents that impose greater risk, as our findings show here. In turn, the value of territory could be further influenced by

409 its potential use, which in the case of B. splendens includes investment in bubble-nest 410 construction for future offspring, a parental behaviour linked to reproductive success 411 (Braddock \& Braddock, 1956; Simpson, 1968; Monvises et al., 2009). This would likely 412 expand the influence that territory value has in relation to life histories, given low-RHP 413 individuals are likely to have also been outcompeted in the past over mates.

414 The effect that life histories have on the value individuals attribute to resources, 415 including territory, have been indicated in fish and other vertebrates (Arnott \& Elwood, 416 2008). For example, a monogamous male contesting over a sole territory may be more 417 aggressive than a polygynous male contesting over several territories (e.g. wild cichlids; 418 O'Connor, Marsh-Rollo, Ghio, Balshine \& Aubin-Horth, 2015). In our study, mating 419 differences were controlled by the absence of females, so the value of the territory could 
420 instead fluctuate depending on investment in bubble-nest construction, whcih was noted in 421 the sample population and has been similarly observed or quantified in captive B. splendens

422

423

424 males in the past (Braddock \& Braddock, 1956; Simpson, 1968). One hypothesis is that bigger nests may be attributed greater fitness value and warrant greater defensiveness because they reflect greater energetic effort and parental investment. This is consistent with many of the underlying assumptions of both the 'desperado effect' and the 'Napoleon strategy', i.e. fish with lower RHP are more driven to fight opponents when they attribute higher fitness-value to resources, especially when resources are linked to reproductive success - in this case related to bubble-nest construction (Grafen, 1987; Morrell et al., 2005). Earlier evidence suggests that the presence and number of nests influence aggression only in interaction with audience effects (Dzieweczynski, Earley, Green \& Rowland, 2005), but there is no evidence whether the effects relate to territory value or whether nests also influence the motivation to fight. Although we did not record measures of bubble-nest construction for our sample population, this is something we are currently investigating to examine effects of resource value on the decision to fight, the assessment strategy used and the level of aggressiveness expressed.

\section{Conclusions}

The use of accurate assessments for the decision to fight is fundamental to our understanding of contests, but it remains largely unexplored (Arnott \& Elwood, 2009a; Reichert \& Quinn, 2017). The primary benefit of accurate assessments of RHP asymmetry is that they can have broader fitness-related benefits than those linked to resource value, such as reducing energy and injury costs (Riechert, 1988; Neat et al., 1998). Previous studies have been unable to definitively identify the use of complex cognitive strategies and theoretical models suggest that the contribution of asymmetry assessment to contest performance may 
445 still be explained by the use of simple cognitive processes (Elwood \& Arnott, 2012).

446 However, our findings suggest that mutual assessment is employed sequentially for managing

447 fight motivation and we argue that at least some cognitive effort is used in improving 448 assessment accuracy by progressively reducing attention to dishonest signals. In contradiction 449 with theory, assessment did not drive avoidance towards relatively more formidable opponents but instead increased fighting motivation towards them. This may be explained by the level of threat imposed in terms of territorial intrusion by bigger and more dangerous opponents. We additionally aim to investigate the role of bubble-nest construction in upcoming studies and anticipate an interest by other researchers to examine how life-histories may affect resource value and its impact on fight motivation and RHP assessment.

\section{REFERENCES}

Allen, J. M., \& Nicoletto, P. F. (1997). Response of Betta splendens to computer animations of males with fins of different length. Copeia, 1997(1), 195-199.

Arnott, G., Beattie, E., \& Elwood, R. W. (2016). To breathe or fight? Siamese fighting fish differ when facing a real opponent or mirror image. Behavioural processes, 129, 11-17.

Arnott, G., \& Elwood, R. (2009b). Probing aggressive motivation in a cichlid fish. Biology Letters, 5(6), 762764.

Arnott, G., \& Elwood, R. W. (2008). Information gathering and decision making about resource value in animal contests. Animal Behaviour, 76(3), 529-542.

Arnott, G., \& Elwood, R. W. (2009a). Assessment of fighting ability in animal contests. Animal Behaviour, 77(5), 991-1004.

Arnott, G., \& Elwood, R. W. (2010a). Startle durations reveal visual assessment abilities during contests between convict cichlids. Behavioural Processes, 84(3), 750-756.

Arnott, G., \& Elwood, R. W. (2010b). Signal residuals and hermit crab displays: flaunt it if you have it!. Animal Behaviour, 79(1), 137-143. 
Beeching, S. C. (1992). Visual assessment of relative body size in a cichlid fish, the oscar, Astronotus ocellatus. Ethology, 90(3), 177-186.

Braddock, J. C., \& Braddock, Z. I. (1959). The development of nesting behaviour in the Siamese fighting fish Betta splendens. Animal Behaviour, 7(3-4), 222-232.

Briffa, M. (2008). Decisions during fights in the house cricket, Acheta domesticus: mutual or self assessment of energy, weapons and size?. Animal Behaviour, 75(3), 1053-1062.

Briffa, M., \& Hardy, I. C. (Eds.) (2013). Introduction to animal contests. Cambridge University Press.

Dzieweczynski, T. L., Earley, R. L., Green, T. M., \& Rowland, W. J. (2005). Audience effect is context dependent in Siamese fighting fish, Betta splendens. Behavioral Ecology, 16(6), 1025-1030.

Earley, R. L. (2010). Social eavesdropping and the evolution of conditional cooperation and cheating strategies. Philosophical Transactions of the Royal Society B: Biological Sciences, 365(1553), 2675-2686.

Elwood, R. W., \& Arnott, G. (2012). Understanding how animals fight with Lloyd Morgan's canon. Animal Behaviour, 84(5), 1095-1102.

Elwood, R. W., Wood, K. E., Gallagher, M. B., \& Dick, J. T. A. (1998). Probing motivational state during agonistic encounters in animals. Nature, 393(6680), 66.

Enquist, M., \& Leimar, O. (1983). Evolution of fighting behaviour: decision rules and assessment of relative strength. Journal of theoretical Biology, 102(3), 387-410.

Enquist, M., \& Leimar, O. (1987). Evolution of fighting behaviour: the effect of variation in resource value. Journal of theoretical Biology, 127(2), 187-205.

Enquist, M., Leimar, O., Ljungberg, T., Mallner, Y., \& Segerdahl, N. (1990). A test of the sequential assessment game: fighting in the cichlid fish Nannacara anomala. Animal Behaviour, 40(1), 1-14.

Enquist, M., Ljungberg, T., \& Zandor, A. (1987). Visual assessment of fighting ability in the cichlid fish Nannacara anomala.. Animal Behaviour.

Gómez-Laplaza, L. M., \& Morgan, E. (2000) Laboratory studies of the effects of short-term isolation on aggressive behaviour in fish. Marine \& Freshwater Behaviour \& Physiology, 33, 63-102.

Grafen, A. (1987). The logic of divisively asymmetric contests: respect for ownership and the desperado effect. Anim. Behav, 35(2), 462-67. 
Hsu, Y., Earley, R. L., \& Wolf, L. L. (2006). Modulation of aggressive behaviour by fighting experience: mechanisms and contest outcomes. Biological Reviews, 81(1), 33-74.

Hsu, Y., Lee, S. P., Chen, M. H., Yang, S. Y., \& Cheng, K. C. (2008). Switching assessment strategy during a contest: fighting in killifish Kryptolebias marmoratus. Animal Behaviour, 75(5), 1641-1649.

Huntingford, F. A. (1984). Some ethical issues raised by studies of predation and aggression. Animal Behaviour, $32(1), 210-215$.

Kokko, H., López-Sepulcre, A., \& Morrell, L. J. (2006). From hawks and doves to self-consistent games of territorial behavior. The American Naturalist, 167(6), 901-912.

Martínez-Cotrina, J., Bohórquez-Alonso, M. L., \& Molina-Borja, M. (2014). Morphological and behavioural correlates of contest success in male yellow-headed geckos, Gonatodes albogularis: sequential assessment or self-assessment?. Behaviour, 151(11), 1535-1554.

McGinley, R. H., Prenter, J., \& Taylor, P. W. (2015). Assessment strategies and decision making in male-male contests of Servaea incana jumping spiders. Animal behaviour, 101, 89-95.

Meejui, O., Sukmanomon, S., \& Na-Nakorn, U. (2005). Allozyme revealed substantial genetic diversity between hatchery stocks of Siamese fighting fish, Betta splendens, in the province of Nakornpathom, Thailand. Aquaculture, 250(1-2), 110-119.

Mesterton-Gibbons, M., \& Heap, S. M. (2013). Variation between self-and mutual assessment in animal contests. The American Naturalist, 183(2), 199-213.

Mesterton-Gibbons, M., Marden, J. H., \& Dugatkin, L. A. (1996). On wars of attrition without assessment. Journal of theoretical Biology, 181(1), 65-83.

Monvises, A., Nuangsaeng, B., Sriwattanarothai, N., \& Panijpan, B. (2009). The Siamese fighting fish: wellknown generally but little-known scientifically. ScienceAsia, 35, 8-16.

Morrell, L. J., Lindström, J., \& Ruxton, G. D. (2005). Why are small males aggressive?. Proceedings of the Royal Society of London B: Biological Sciences, 272(1569), 1235-1241.

Neat, F. C., Taylor, A. C., \& Huntingford, F. A. (1998). Proximate costs of fighting in male cichlid fish: the role of injuries and energy metabolism. Animal Behaviour, 55(4), 875-882. in the molecular pathways underlying the repeated evolution of sociality in African cichlids?. Hormones and behavior, 75, 160-168. 
Parker, G. A. (1974). Assessment strategy and the evolution of fighting behaviour. Journal of theoretical Biology, 47(1), 223-243.

Payne, R. J. (1998). Gradually escalating fights and displays: the cumulative assessment model. Animal Behaviour, 56(3), 651-662.

Payne, R. J., \& Pagel, M. (1996). Escalation and time costs in displays of endurance. Journal of Theoretical Biology, 183(2), 185-193.

Payne, R. J., \& Pagel, M. (1997). Why do animals repeat displays?. Animal Behaviour, 54(1), 109-119.

Polgardani, N. Z., Rouzbehani, S., \& Parsaiyan, M. (2017). Male Siamese fighting fish (Betta splendens) recognize resource holding power of opponents. Aquaculture, Aquarium, Conservation \& LegislationInternational Journal of the Bioflux Society (AACL Bioflux),10(4) 977-982.

Prenter, J., Elwood, R. W., \& Taylor, P. W. (2006). Self-assessment by males during energetically costly contests over precopula females in amphipods. Animal Behaviour, 72(4), 861-868. engagement for resource contests in a social fish. Animal Behaviour, 82(1), 93-99.

Reichert, M. S., \& Quinn, J. L. (2017). Cognition in contests: mechanisms, ecology, and evolution. Trends in ecology \& evolution, 32(10), 773-785.

Riechert, S. E. (1988). The energetic costs of fighting. American Zoologist, 28(3), 877-884.

Riechert, S. E. (1998). Game theory and animal contests. Game theory and animal behavior, 64-93.

Romano, D., Benelli, G., Donati, E., Remorini, D., Canale, A., \& Stefanini, C. (2017). Multiple cues produced by a robotic fish modulate aggressive behaviour in Siamese fighting fishes. Scientific Reports, 7(1), 4667.

Schnell, A. K., Smith, C. L., Hanlon, R. T., \& Harcourt, R. (2015). Giant Australian cuttlefish use mutual assessment to resolve male-male contests. Animal behaviour, 107, 31-40.

Simpson, M. J. A. (1968). The display of the Siamese fighting fish, Betta splendens. Animal Behaviour Monographs, 1, i-73. 
Tsai, Y. J. J., Barrows, E. M., \& Weiss, M. R. (2014). Pure Self-Assessment of Size During Male-Male Contests in the Parasitoid Wasp Nasonia vitripennis. Ethology, 120(8), 816-824.

Turner, G. F. (1994). The fighting tactics of male mouthbrooding cichlids: the effects of size and residency. Animal Behaviour, 47(3), 655-662.

Walsh, J. T., \& Iyengar, V. K. (2015). Win, lose, or draw: effects of residency, size, sex, and kinship on high-stakes larval contests in a moth. Ethology, 121(8), 733-739. 
Table 1. Linear effects on the two sequential startle-durations by weight and fin-length residuals of focal fish, opponents, and their difference.

592

593

594

595

596

597

598

599

600

601

602

603

604

605

606

607

608

609

610

611

612

613

614

615

616

617 (a) Weight:

Focal Opponent

Difference

(b) Fin residuals:

Focal Opponent

Difference

Bold type indicates associations with statistical significance of $P<0.05$ $\underline{\text { First startle }}$

\section{$\underline{\text { Second startle }}$}

$\begin{array}{llllll}R^{2} & F_{2,44} & P & R^{2} & F_{2,44} & P\end{array}$

$0.173 \quad 17.38<0.001$ $\begin{array}{lll}0.076 & 8.20 & 0.007\end{array}$

$0.149 \quad 8.97 \quad 0.005$

$\begin{array}{lll}0.131 & 6.75 & 0.013\end{array}$

$0.308 \quad 18.72<0.001$

$\begin{array}{lll}0.206 & 10.93 & 0.002\end{array}$

$\begin{array}{llllll}\mathbf{0 . 1 7 3} & \mathbf{8 . 7 4} & <0.001 & 0.042 & 1.82 & 0.174 \\ \mathbf{0 . 0 9 0} & \mathbf{4 . 5 6} & \mathbf{0 . 0 1 6} & 0.040 & 1.74 & 0.187 \\ \mathbf{0 . 1 5 6} & \mathbf{7 . 8 7} & \mathbf{0 . 0 0 1 2} & 0.024 & 1.06 & 0.355\end{array}$


FIGURE LEGENDS:

619

620 Figure 1. Measures of caudal (a) and anal fin length (b) as extracted from traces by applying 621 graph paper on the glass tank-wall where fish rested.

622 Figure 2. The startle duration of focal fish varied individually with their own weight (a), the 623 weight of their opponent (b) and the difference between them (c). This was observed on both 624 sequential occasions, first and second startle. Contrary to predictions, the motivation to 625 recommence fighting was greater for smaller fish against relatively bigger opponents that 626 differed the most from them.

627

Figure 3. Contest behaviour exhibited by focal fish towards relatively bigger opponents 628 (black circles) or relatively smaller opponents (white circles). The total display time of fish was unrelated to their own weight (a), but positively related to their opponents' weight (b).

630 Similarly, their number of attacks were not strongly related to their own weight (c), but 631 positively related to their opponent's weight $(\mathbf{d})$. Overall, fish were significantly more aggressive when fighting bigger opponents.

633

634

635

636

637

638

639

640 
641 FIGURE 1

642

643

(a)

(b)

644

645

646
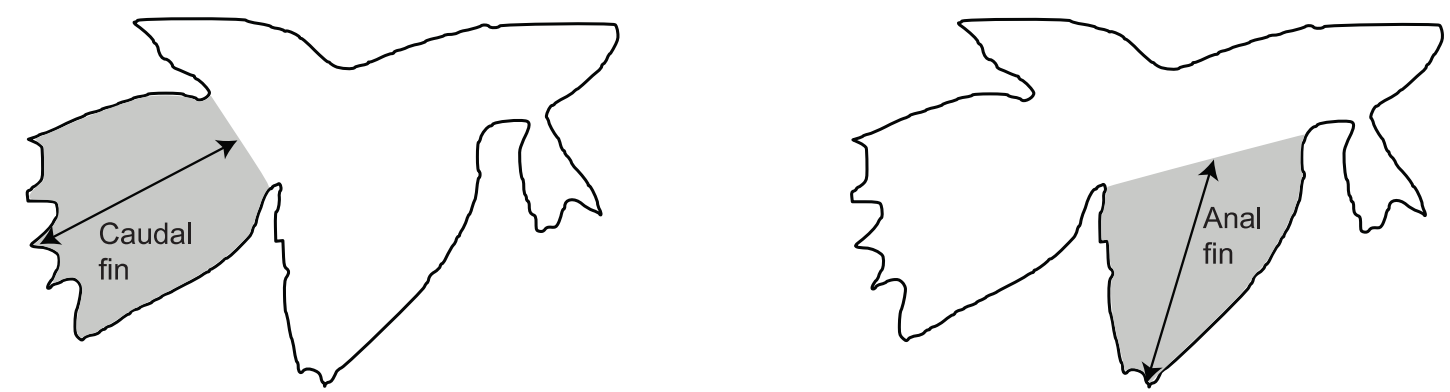

647

648

649

650

651

652

653

654

655

656

657

658

659

660

661

662

663

664

665

666

667

668 
669

FIGURE 2

670

671

672

673

674

675

676

677

678

679

680

681

682

683

684

685

686

687

688

689

690

691

692

693

694

695

696

697

698 (a)

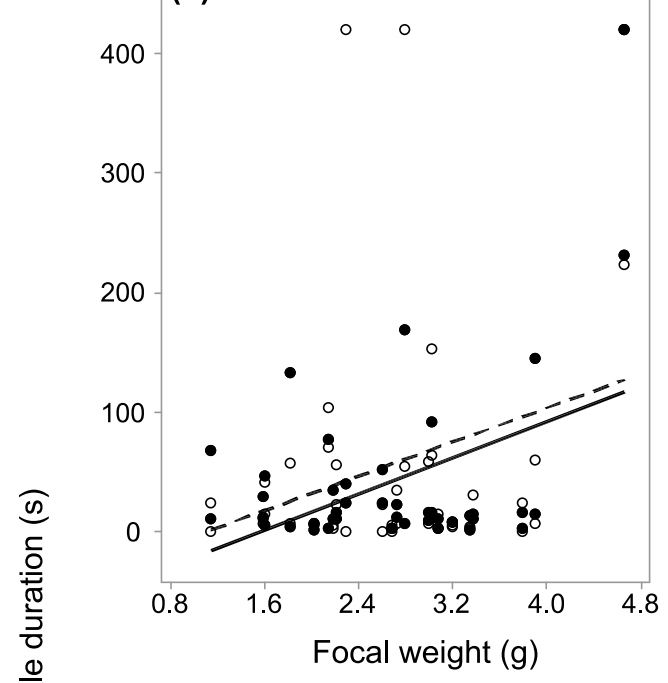

(b)

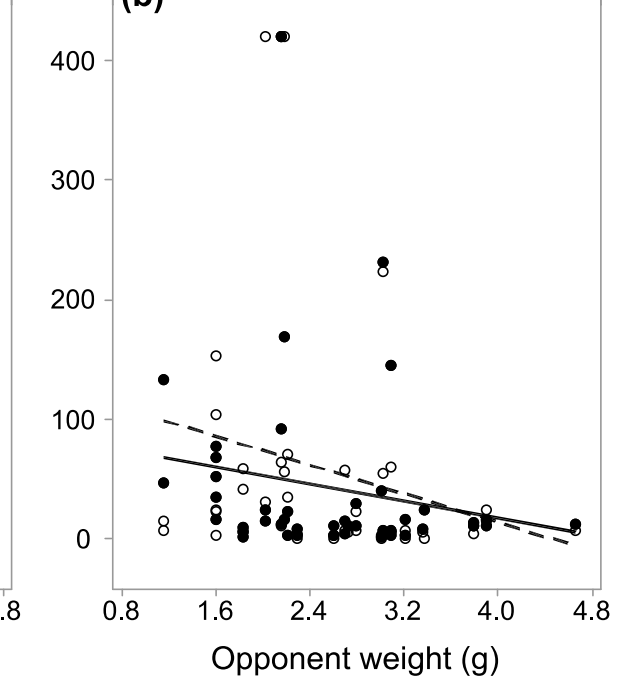

क

(c)

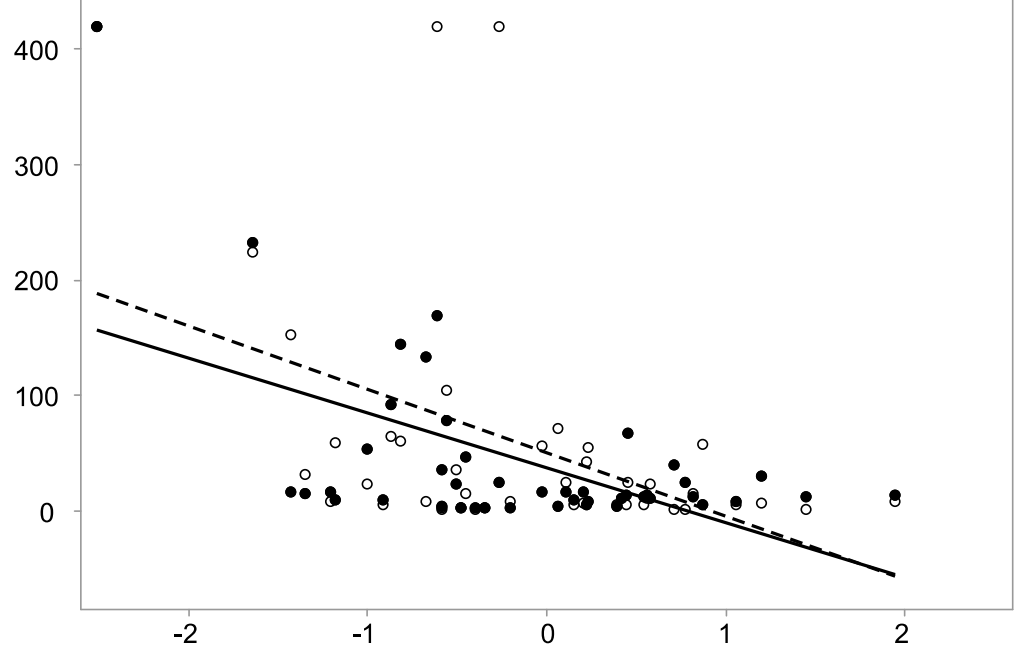

Difference in wet weight (g) [opponent- focal]

$\rightarrow$ 1st Probe 2nd Probe 
700

701

702

- Bigger opponent

- Smaller opponent

703

704

705

706

707

708
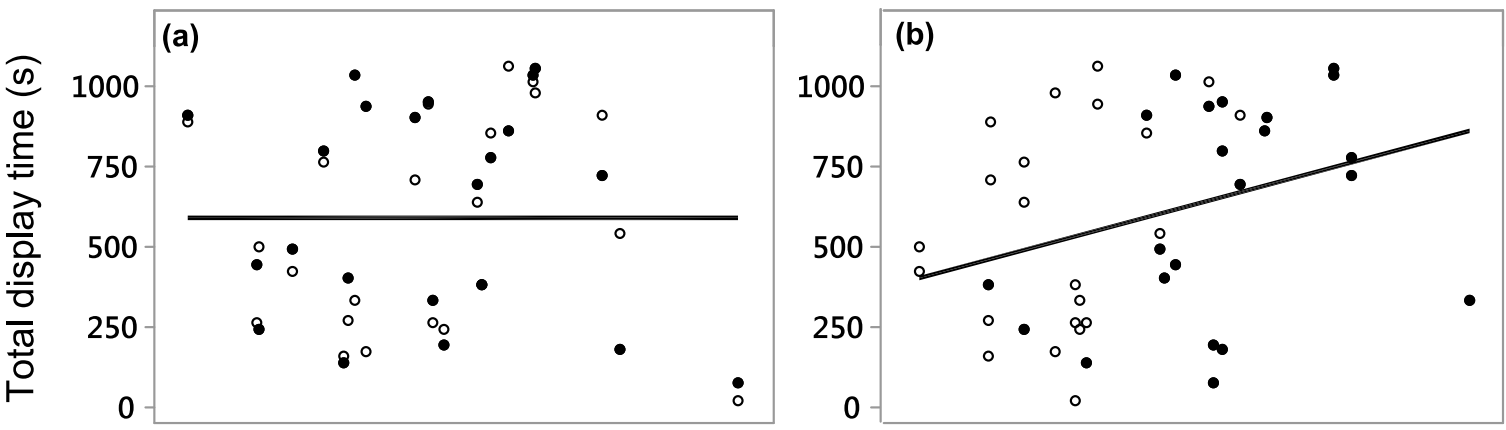

709

710

711

712
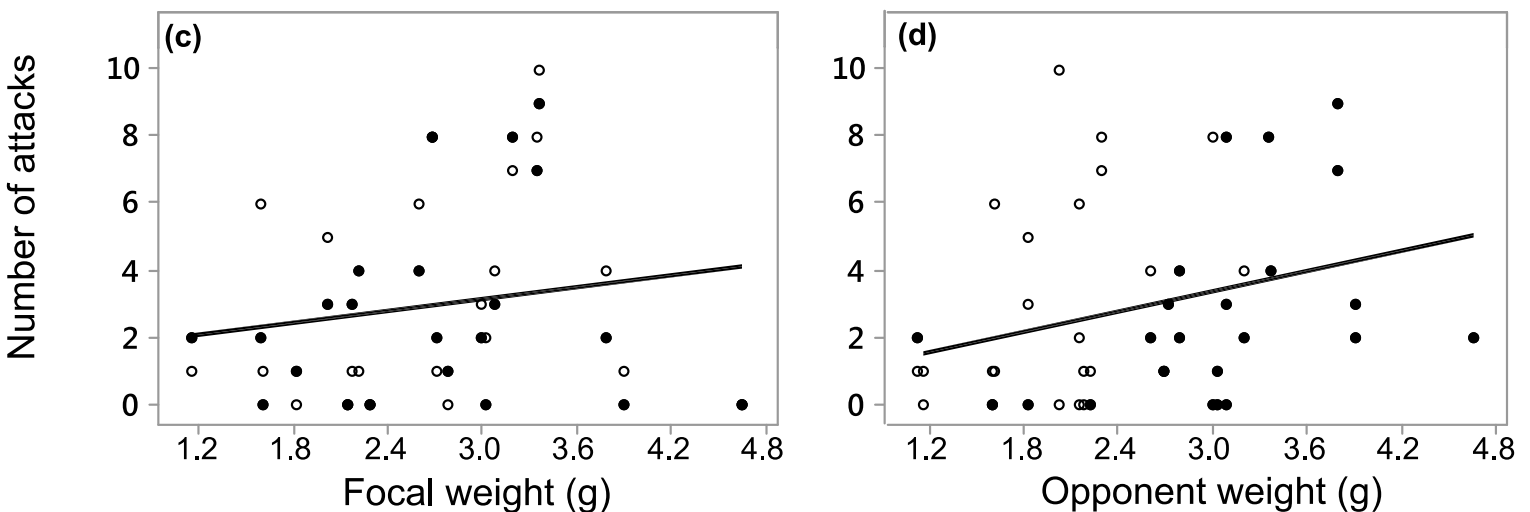

714

Focal weight $(\mathrm{g})$

Opponent weight (g)

715

716

717

718

719

720

721

722

723

724

725

726

727

728 
